\title{
The wear characteristics of cemented tungsten carbide tools in machining oil palm empty fruit bunch particleboard
}

\begin{abstract}
A series of machining experiments on the Oil Palm Empty-Fruit Bunch (OPEFB) particle board were carried out using tungsten carbide tools, to ascertain the predominant mechanism of tool wear when machining this material. The experiments were carried out using a high speed lathe, which machined a rotating disc of the OPEFB particle board. It was found that mechanical abrasion and micro-fracture was the primary mode of tool failure when machining OPEFB particle board. The low cutting temperature recorded during the machining experiments provides compelling evidence to eliminate any significant effect of electrochemical and oxidation mechanisms on the wear of tungsten carbide tools. Therefore, the wear of cemented tungsten carbide tools when machining OPEFB particle board was predominantly by mechanical wear mechanisms. The results of this study implies that the high tool wear experienced during the machining of OPEFB particle board, may limit its use in the manufacture of value-added products, unless the boards are priced competitively in the market.
\end{abstract}

Keyword: Machining; Particleboard; Tool-wear; Abrasive material; Mechanical abrasion 